\title{
Diversification of Pakistani Amelogenin-Y-Null Male Haplotypes
}

\author{
Nasir Siddique $\mathbb{D}^{1,2}$ Ahmad Ali Shahid, ${ }^{3}$ and Kalsoom Sughra $\mathbb{D}^{1}$ \\ ${ }^{1}$ Department of Biochemistry \& Biotechnology, University of Gujrat, Gujrat, Pakistan \\ ${ }^{2}$ DNA and Serology Section, Punjab Forensic Science Agency, Lahore, Pakistan \\ ${ }^{3}$ National Centre of Excellence in Molecular Biology, University of the Punjab, Lahore, Pakistan \\ Correspondence should be addressed to Kalsoom Sughra; kalsoom.sughra@uog.edu.pk
}

Received 16 February 2021; Accepted 22 April 2021; Published 5 May 2021

Academic Editor: José A. Castro

Copyright ( 2021 Nasir Siddique et al. This is an open access article distributed under the Creative Commons Attribution License, which permits unrestricted use, distribution, and reproduction in any medium, provided the original work is properly cited.

\begin{abstract}
Amelogenin is a common sex typing marker encountered in forensic case work. Phenotypically normal males have been reported in the literature who exhibit anomalous amelogenin allele. These males express only a single amelogenin peak representing AMEL$\mathrm{X}$ and are called as AMEL-Y-null males. Gender misclassification of such individuals is an obvious consequence of this mutation, as a male sample would falsely appear to be a female sample. This study was aimed to attribute the AMEL-Y-null male DNA profiles encountered in forensic casework in the Pakistani population to appropriate phylogenetic clade based on shared ancestry. A total of 18 null AMEL-Y males were screened out of the sample pool of 5000 male individuals, reflecting mutational frequency of $0.36 \%$. A common phylogenetic ancestor is suggested for 17 individuals, based on computational analysis of the Y-STR haplotypes, shown to be belonging to the J haplogroup while only one sample belonged to the R group. The samples in J groups showed homology with subclades J2b2a M241 and J2b2a PH1648, while R group individual showed 100\% homology with R1a. Data are reported after haplotype network development of AMEL-Y-null Pakistani males using Network 10.0 for the study of evolutionary distances and emergence of nodes.
\end{abstract}

\section{Introduction}

Human gender identification has important applications in forensic casework [1], parentage determination [2], archaeological analysis [3], DNA data basing, and blood sample storage. Sex typing is vital in medical diagnosis of sex-linked diseases and forensic science. Moreover, sex determination is of pronounced significance as additional information in criminal investigations as well as in identification of missing persons, no-suspect cases, and ancient DNA studies. The Y-chromosome sex marker amelogenin is extensively used for determination of chromosomal sex of an unknown individual and differentiating the comparative influences of male and female DNA in the mixed forensic samples $[4,5]$.

Amelogenin is present on both $\mathrm{X}$ and $\mathrm{Y}$ chromosomes where it is denoted as AMEL-X and AMEL-Y. AMEL-X is located on the distal short arm of the $\mathrm{X}$ chromosome in the p22.1-p22.3 region, while AMEL-Y is present near the centromere of the $\mathrm{Y}$ chromosome at $\mathrm{p} 11.2[6,7]$. There is a small variation between AMEL-X and AMLEY, attributed to a 6 bp deletion in the third intron of the AMEL-X isoform $[6,8,9]$. While this deletion has no phenotypical manifestation, it is, however, conventionally exploited in forensic DNA analysis to differentiate male and female DNA profiles. Many primer sets have been developed for the amplification of the amelogenin gene to use it as a sex typing test $[8,10-12]$. The most commonly used primer set executes PCR amplification, resulting in AMEL-X/AMEL-Y amplicons of $106 \mathrm{bp}$ and $112 \mathrm{bp}$, respectively [1].

The usefulness of the amelogenin marker in forensics has been repeatedly called into question, as many cases of the failure of the amelogenin marker to correctly determine the sex of DNA donors have been reported $[13,14]$. Apparently the failure to amplify AMEL-Y denotes the lack of Y-DNA, but, in fact, the $Y$ chromosome is present but the region of the $Y$ chromosome having AMEL-Y is deleted. The reported null AMEL-Y males vary by population, fluctuating from $0.018 \%$ to $8 \%$, with the uppermost frequencies of amelogenin failure present in populations of the Indian 
subcontinent [5]. Mostly, the AMEL-Y-null males reported are due to the fragment deletion in the $\mathrm{Y}$ chromosome including AMEL-Y $[15,16]$.

A Y-chromosomal haplogroup is a cluster or a family of $\mathrm{Y}$ chromosomes interrelated by descent or ancestry determined by an explicit set of Y-chromosomal markers. Y haplogroups play a vital role in understanding past migrations and demographic progressions that wrought modern populations [17]. Y-SNP analysis was conventionally conducted for haplogroup designation; however, Y-SNP analyses are time consuming and laborious. New approaches have recently been explored, for example, in silico analysis based on algorithms assignment created with Y-STR profiling data [18-20]. While the accuracy of in silico haplogroup assignment methods was initially under question, a number of recent validation studies including sample groups with both Y-SNP and Y-STR data acclaimed accuracy of more than $95 \%$. The reliability of analysis is further reinforced when using datasets of at least twelve Y-STR loci with more inflexible definite haplogroup assignment thresholds [21-24]. In the forensic perspective, there are adequate Y-STR data accessible that can be explored for population genetics [25-27]. In the current study, we have conducted phylogenetic analysis of the Pakistani AMEL-Ynull males.

\section{Materials and Methods}

2.1. Sample Collection. The Punjab Forensic Science Agency (PFSA), Lahore, Pakistan, DNA Database (Bode Match Software) comprises thousands of profiles generated during forensic casework over the years. AMEL-Y-null male individuals search in this database was conducted by filtering out the male individuals with genotype as $\mathrm{X}$, at the amelogenin locus. Eighteen AMEL-Y-null males were identified out of the total male sample pool of 5000 . Blood samples of these 18 individuals were aseptically collected with the consent of the donors.

2.2. DNA Extraction and Quantification. DNA extraction and purification from the blood samples was carried out by an organic extraction method employing Phenol-Chloroform-Isoamyle alcohol (PCI) extraction protocol followed by nucleic acid purification by ethanol precipitation [28]. Quantification of the DNA extracts was performed on an ABI ${ }^{\circledR}$ Real-Time PCR 7500 system using the Quantifiler ${ }^{\circledR}$ Duo DNA Quantification Kit according to the manufacturer's protocol [29].

2.3. STR and Y-Profiling. Y-STR profiling was conducted using an optimal target input DNA (0.5-1.0 ng) using the AmpFlSTR ${ }^{\circledR}$ Y-Filer ${ }^{\mathrm{TM}}$ PCR Amplification Kit (Applied Biosystems), at DYS19, DYS385, DYS389I/II, DYS390, DYS391, DYS392, DYS393, DYS437, DYS438, DYS439, DYS448, DYS456, DYS458, DYS635, and Y-GATA-H4 Y-chromosome loci [30]. The manufacturer's recommended protocol was used for the amplification reactions. PCR
Amplification of the all samples was carried on the ABI Veriti $^{\mathrm{TM}} 96$ Well Thermal Cycler.

Amplification with the ABI AmpFlSTR ${ }^{\circledR}$ Identifiler ${ }^{\circledR}$ Plus PCR Amplification Kit and ABI Globalfiler ${ }^{\mathrm{TM}}$ was also carried out for the null samples following recommendations by the manufacturer [31, 32]. Positive and negative amplification controls were used for evaluating the efficiency of the amplification.

The amplified products were electrophoretically separated on the ABI 3500 series Genetic Analyzer (Applied Biosystems) using an injection time of 5 seconds at $3 \mathrm{kV}$, whilst POP-4 TM, GeneScan 600 LIZ ${ }^{\circledR}$ Size Standard, loading mix, and other reagents were used according to the manufacturer's instructions. Genotyping results were analyzed using GeneMapper ${ }^{\circledR}$ ID-X software version 1.4 [33].

2.4. Haplogroup Prediction. The haplotypes of the AMEL-Ynull Pakistani males sample obtained through Y-STR profiling were submitted to the web-based software Nevgen Y-DNA haplogroup predictor (http://www.nevgen.org). Nevgen is a typical interpreter which predicts haplogroup based on STR profiles. Predicted haplogroup, fitness score, and probability were calculated for all the samples under study. Haplotypes comprising 17 Y-STR loci of all the samples were uploaded to Nevgen. Haplogroup was assigned to the samples on the basis of highest probability scores [20].

2.5. Statistical Analysis. The genetic relationship between haplotypes of AMEL-Y-null Pakistani males was analyzed using NETWORK 10.0 software (http://www.fluxusengineering.com). Median joining methods were employed using the frequency $>1$ criterion with active external rooting and MJ square [34-36]. For network construction, the duplicated locus DYS385 was not used since the constituent loci are not distinguished in this assay.

Time estimation was performed using a default mutation rate of 01 mutation per 20180 years in NETWORK 10.0 software. Using SEQ-1 arbitrarily as an ancestral node, time was estimated for each AMEL-Y-null male SEQ group as descendent node separately as well as with all sequences.

Forward simulation was carried out using the default setting of a NETWORK 10.0 mutation rate of 01 mutation per 20180 years, maximum population decrease/increase per generation at 50 and 1000 number of population equally distributed. Mismatch mutation rate was also determined using the same software.

\section{Results and Discussion}

3.1. AMEL-Y-Null Males in the Pakistani Population. Even though amelogenin is the workhorse of DNA sex determination for decades, the failures of this marker have been reported continuously from different populations. Expansion in CODIS core loci in the USA was proposed [37], and 20 loci are now categorized as core CODIS loci since 2017. The new commercial kits include additional autosomal STR loci and a Y-STR locus to help in sex determination in case amelogenin fails to amplify. 


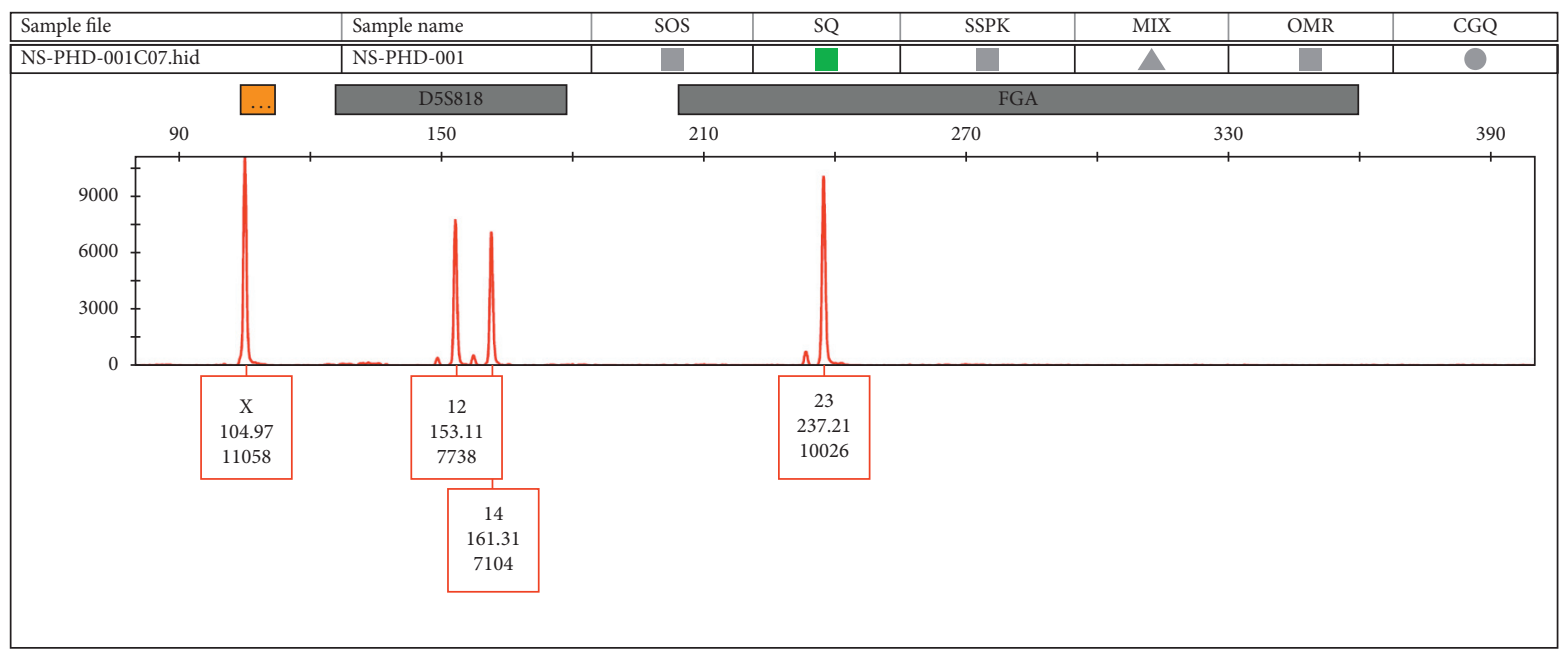

(a)

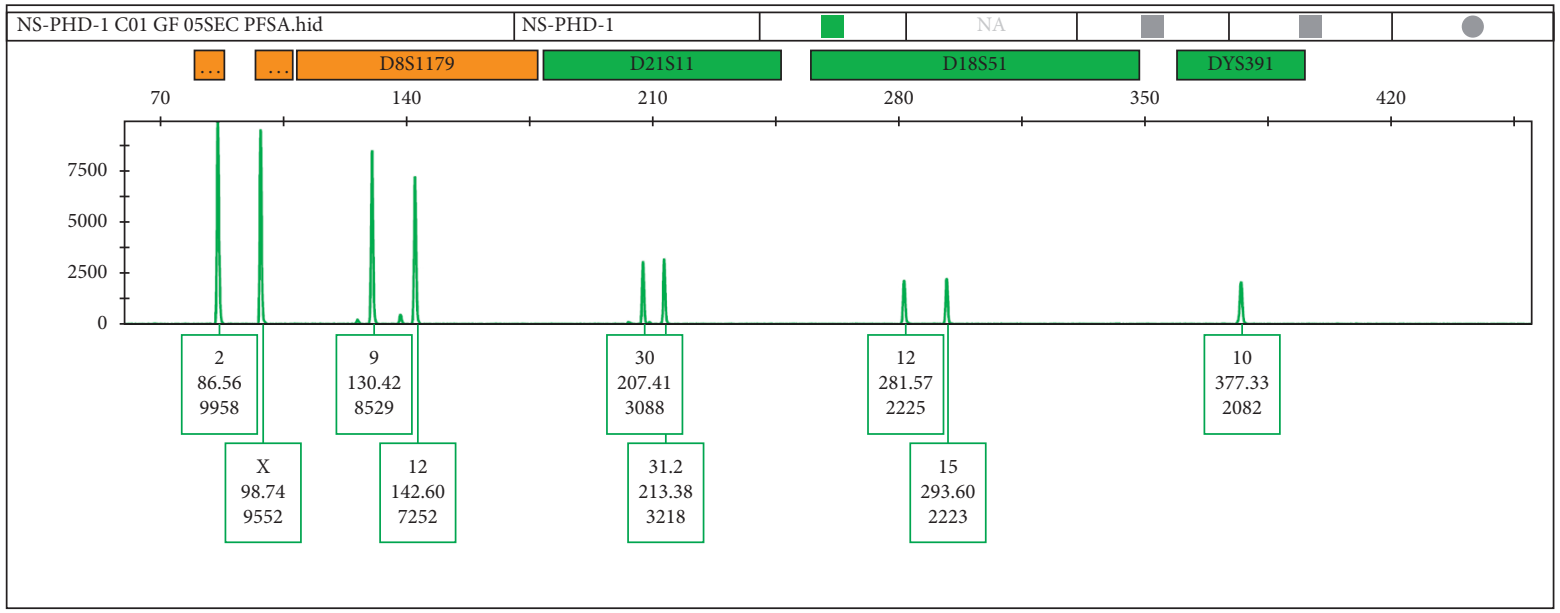

(b)

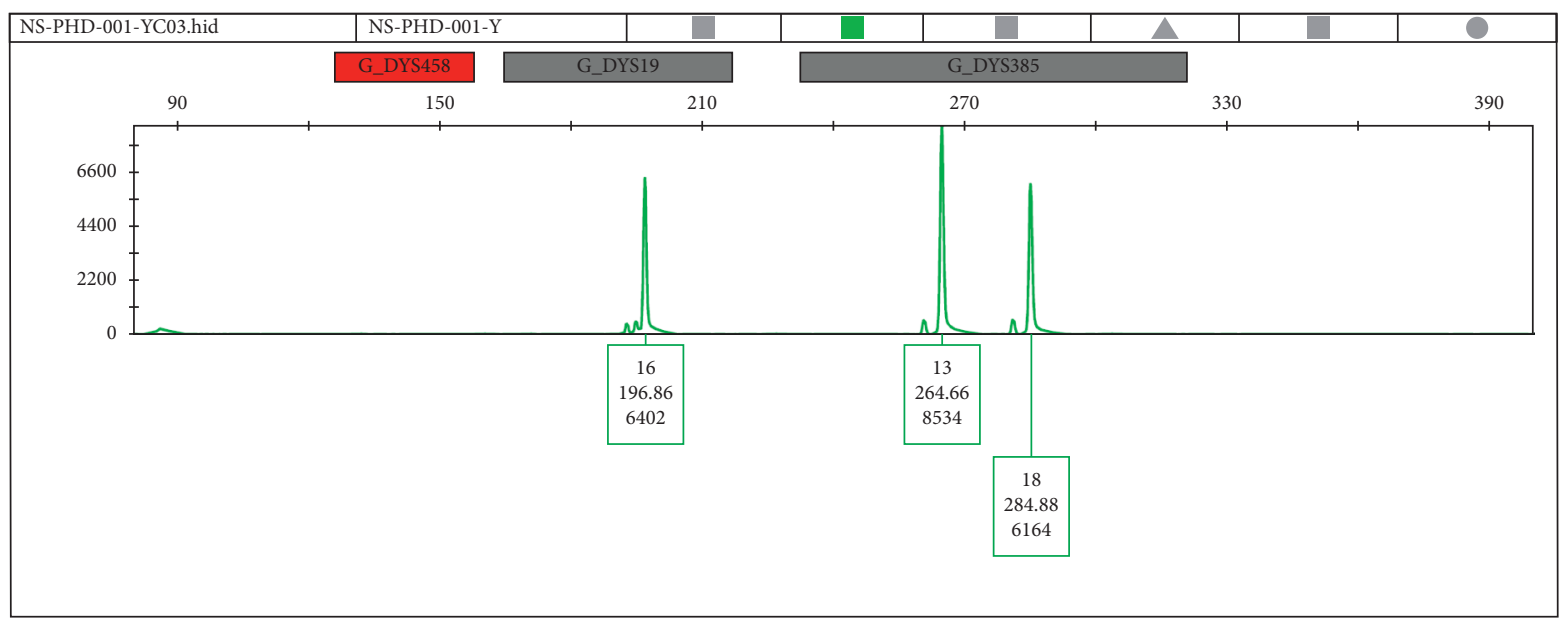

(c)

FIgURE 1: A representative STR electropherogram of AMEL-Y-null Pakistani males. (a) Panel of STR profile obtained using the Identifiler Plus STR system showing the absence of Amel-Y. (b) Panel of STR profile obtained using the Global Filer STR system showing the absence of Amel-Y. (c) Panel of haplotype profile obtained using the Y-filer STR system showing the absence of DYS458. 


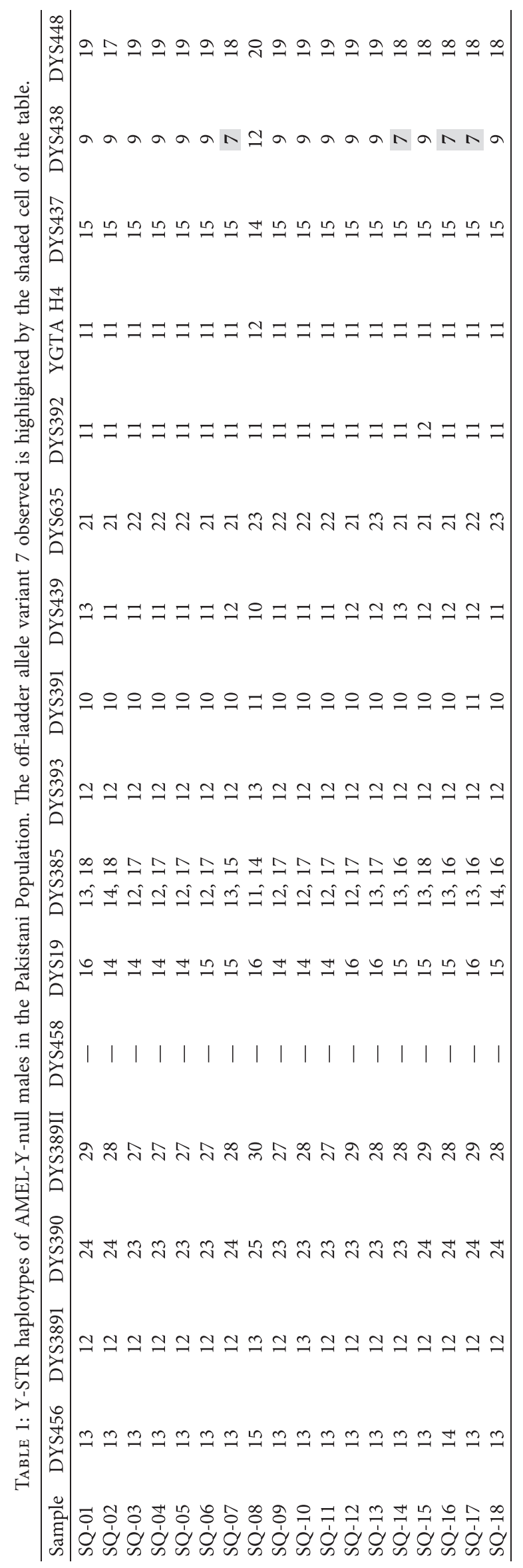



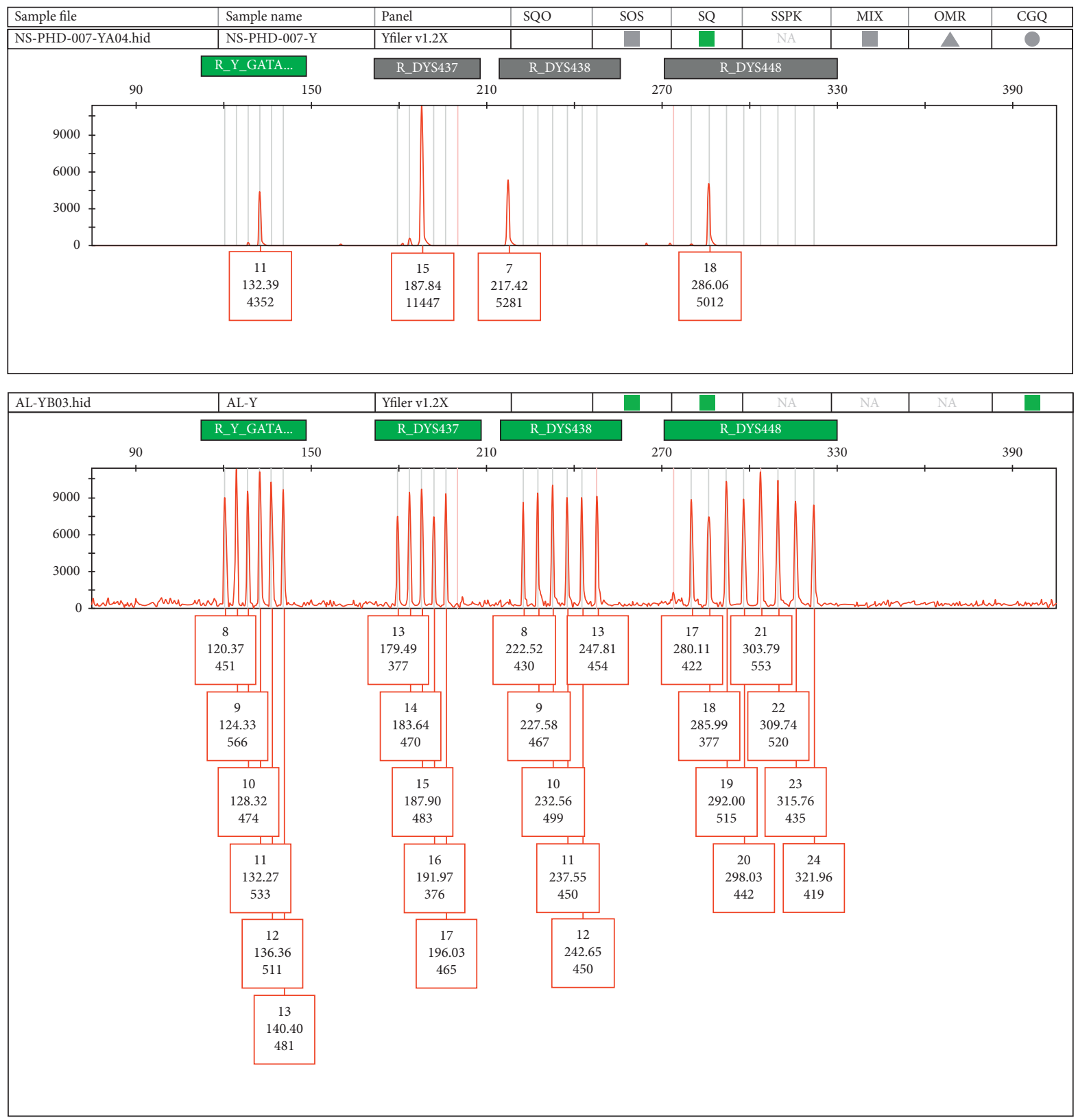

Figure 2: A profile of AMEL-Y-null male with off-ladder allele variant 7 at DYD438.

The local database of PFSA, Lahore, Pakistan, was explored for the DNA profiles of male reference samples incorrectly genotyped as females. Eighteen male individuals showed a female genotype, depicted by the nonappearance of the $112 \mathrm{bp} \mathrm{AMEL-Y} \mathrm{peak} \mathrm{(Figure} \mathrm{1(a)).} \mathrm{The} \mathrm{frequency} \mathrm{of}$ the AMEL-Y-null allele was calculated as 0.36\% (18/5000) in the Pakistani population. These samples were labeled as SQ1-SQ-18. The frequency of AMEL-Y-null males in various populations has been studied and has been shown to vary in different populations ranging from 0.037 to $10 \%$ [38-42].

The AMEL-Y-null males who showed amelogenin-Y amplification failure with the Identifiler plus kit also showed the AMEL-Y negative results with Globalfiler ${ }^{\mathrm{TM}}$; however, all eighteen samples were typed as male correctly due to the presence of DYS391 and Y-InDel loci in the Globalfiler kit
(Figure 1(b)). This concordance of AMEL-Y null in both PCR systems ruled out the possibility of point mutation in the primer binding site as both use different sets of primers for AMEL amplification. These results, coupled with the finding that DYS458 did not amplify with the Y-filer kit, suggested that there is a fragment deletion in the $\mathrm{p}$ arm of the $\mathrm{Y}$ chromosome in these eighteen individuals (Figure 1(c)).

Subsequent amplification of the $16 \mathrm{Y}-$-filer $^{\mathrm{TM}}$ Y-STR loci gave additional conclusive results that these 18 samples are from true male individuals.

3.2. Haplotypes of AMEL-Y-Null Males. The Y-STR profiles of null AMEL-Y males share a maximum of fifteen alleles and a minimum of only one allele, i.e., SQ-8. The incredibly 
AMELY null Pakistani male haplogroups

12

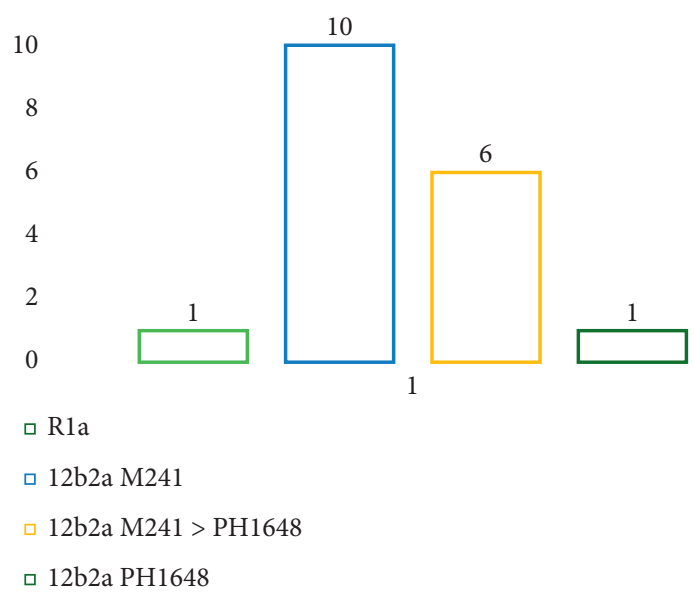

Figure 3: Graphical representation of relative abundance of different haplogroups observed in AMEL-Y-null Pakistani males.

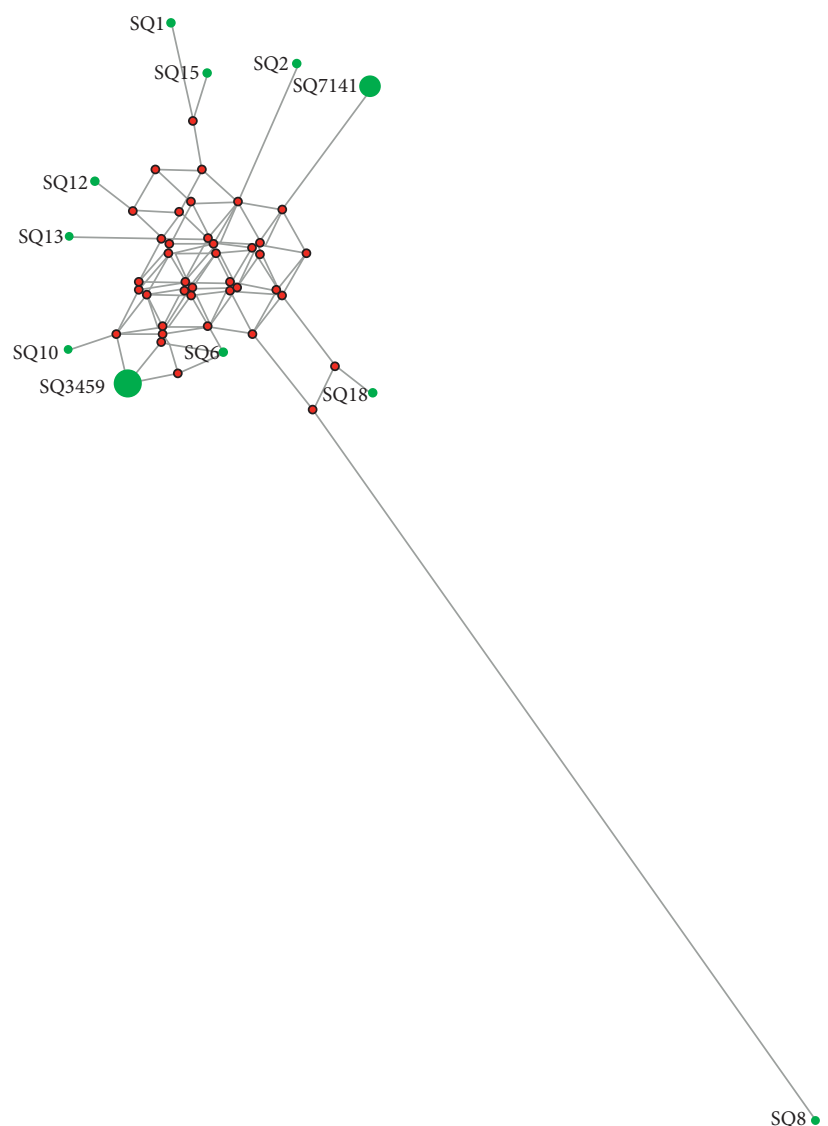

(a)

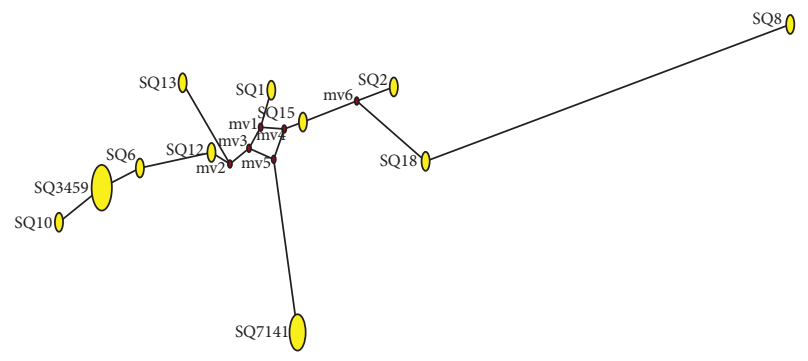

(b)

FIGURE 4: YSTR haplotype network (a) and phylogenetic tree (b) of AME-Y-null Pakistani males drawn using the median joining method.

analogous haplotypes of 5 samples (sharing of maximum 15 alleles) indicated the possibility of similar phylogenetic origin. The amelogenin-Y dropout in all eighteen Pakistani male samples was accompanied by the same pattern of insertion at the Y-InDel locus showing genotype 2 at this locus, and a genotype of DYS391 was observed as 10 in all samples except for sample SQ-8 and SQ-17 that showed genotype 11 at this locus.

The haplotypes of all the Pakistani AMEL-Y negative males showed the deletion at DYS458 while all other alleles at different loci were correctly genotyped. These findings further strengthened the concept of having fragment 


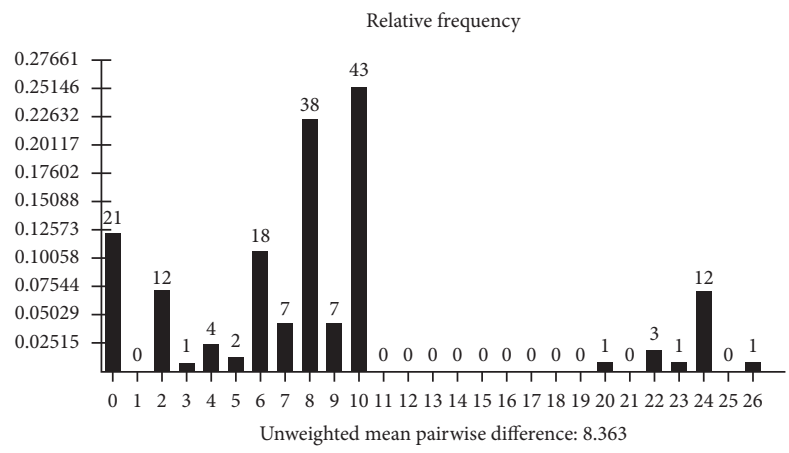

FIgURE 5: Mismatch frequency of AMEL-Y-null Pakistani male haplotypes.

TABLE 2: Time estimation of mutation from SQ-1 to different variants (SQ-2 to SQ-18) of AMEL-Y-null male Pakistani individuals in Rho and years.

\begin{tabular}{lccccc}
\hline Sr. No. & Sample & Age in mutation (Rho) & Standard deviation (sigma) & Age in years & Standard deviation in years \\
\hline 1 & 2 & 4 & 0.70711 & 80,720 & 14269.415 \\
2 & $3,4,5,9$ & 8.57 & 1.2122 & 172,971 & 24467.854 \\
3 & 6 & 4 & 0.86603 & 80,720 & 17476.393 \\
4 & $7,14,16,17$ & 8 & 1.9596 & 161,440 & 39544.562 \\
$\mathbf{5}$ & $\mathbf{8}$ & $\mathbf{1 5}$ & $\mathbf{2 . 2 3 6 1}$ & $\mathbf{3 0 2 , 7 0 0}$ & $\mathbf{4 5 1 2 3 . 8 5 1}$ \\
6 & 10 & 6 & 0.70711 & 121,080 & 14269.415 \\
7 & 12 & 3 & 0.5 & 40,360 & 10090 \\
8 & 13 & 1.5 & 0.70711 & 60,540 & 14269.415 \\
9 & 15 & 5 & 0.70711 & 30,270 & 14269.415 \\
10 & 18 & 9.5263 & 1.9502 & 100,900 & 20180 \\
11 & Overall & & & 192,241 & 39355.264 \\
\hline
\end{tabular}

deletion in the $\mathrm{Y}$ chromosome of these individuals. Three different deletion patterns of AMEL-Y-null cases have been reported in literature: AMEL-Y-DYS456, AMEL-Y-DYS458, and AMEL-Y-DYS458-DYS522 [42-44]. The deletion observed in all eighteen AMEL-Y-null male samples of the Pakistani population was found to be AMEL-Y and DYS458. The haplotypes of AMEL-Y-null Pakistani males are enlisted in Table 1.

Despite few dissimilarities, most of the Y STR loci in AMEL-Y-null males have the similar haplotypes suggesting that these deletions may possibly have occurred in the same paternal lineage [45]. Five of the samples (SQ 3, $4,5,9$, and 11) show identical haplotypes. Another group (SQ 7, 14, 16, and 17) shares the same Y haplotype. An off-ladder allele variant was observed at DYS438 in the haplotypes of SQ 7, 14, 16, and 17 which was calculated as 7 (Figure 2). The electropherograms of these samples are illustrated in Figure S1. SQ-8 has a unique versatile haplotype among the eighteen AMEL-Y-null Pakistani males.

3.3. Haplogroups of AMEL-Y-Null Males. Haplogroup and subclades were predicted using the Nevgen Y-DNA haplogroup predictor for all eighteen AMEL-Y-null males using their Y STR haplotypes. SQ-1 showed the highest probability value of $99.7 \%$ with J group and subclade J2b2a M241. Seventeen out of eighteen AMEL-Y-null males have the Y-STR profiles which showed the maximum probability with haplogroup J while only one (SQ-8) showed 100\% homology with the R group (Figure 3).

Y-DNA haplogroup J evolved in the ancient Near East and was carried into North Africa, Europe, Central Asia, Pakistan, and India. J haplogroup ancestors spread in the Fertile Crescent (Middle East area). Middle Eastern traders brought this genetic marker to the Indian subcontinent $[46,47]$. Y-DNA haplogroup R-M207 is ascended approximately 27,000 years ago in Asia, having two subclades R1 and R2. In India and Pakistan, this is one of the prevalent haplogroups [48]. Detailed probability values of AMEL-Ynull Pakistani males with different haplogroups and subclades as determined through Nevgen Y-DNA haplogroup predictor are given in Table S1.

3.4. Statistical Analysis. The median joining method was used for the network preparation using NEWTWORK 10.0 software to study the genetic relationships between haplotypes of AMEL-Y-null Pakistani males (Figure 4(a)). The phylogenetic tree showed that SQ-8 is genetically distant from other AMEL-Y-null Pakistani males (Figure 4(b)).

The total number of mutations disregarding the torso is 49 , estimated number of mutations of the shortest tree within the torso is 3 , and estimated number of mutations of the shortest tree is 52 .

The statistical data for this phylogenetic analysis showed that the total number of mutations disregarding the torso is 49 , estimated number of mutations of the shortest tree 
within the torso is 3 , and estimated number of mutations of the shortest tree is 52 . The number of mutations at each genetic locus was observed except DYS392. Maximum five mutations were present at DYS389IIab (Table S2).

Forward simulation was performed using a sequence length of 369 with the number of generations 1000 and mutation rate of one mutation every 20180 years. Pairwise mismatch frequency was calculated using NETWORK 10.0. The unweighted mean pairwise difference was observed to be 8.363. Figure 5 demonstrates the relationship between pairwise differences and their relative frequencies among AMEL-Y-null males in the Pakistani population.

Default mutation rate of one mutation per 20180 was used for time estimation in years and Rho.

Time estimation was carried out using the default mutation rate of 01 mutation per 20180 years [49] in NETWORK 10.0 software. The maximum time difference was observed in the SQ-1-SQ-8 302,700 years and 15 mutations (Rho) (Table 2).

\section{Conclusions}

The current study of 18 AMEL-Y-null males out of a total of 5000 male reference samples with the frequency of $0.36 \%$ in Pakistani populations emphasizes the requirement for the employment Y-STR markers for sex typing to acquire accurate results. Dropout of DYS458 in all samples and high frequency of Y-STR allele sharing (up to 15 alleles in 5 cases) reflect an overall phylogenetic ambiance amongst them. Y-chromosome fragment deletion was implied on the basis of simultaneous null allele finding at AMEL-Y and DYS458. A majority of the AMEL-Y-null males in the Pakistani population showed the maximum homology with haplogroup J2b2a. Phylogenetic analysis demonstrated that one individual SQ-8 is far different from other seventeen AMEL$\mathrm{Y}$-null males involved in the study.

\section{Data Availability}

Data are available on reasonable request.

\section{Conflicts of Interest}

The authors declare no conflicts of interest.

\section{Acknowledgments}

The authors are thankful to Dr. Mohammad Ashraf Tahir (Director General), Punjab Forensic Science Agency, Lahore, Pakistan, for providing research facilities for this study.

\section{Supplementary Materials}

Figure S1: electropherograms of AMEL-Y-null male with off-ladder allele variant 7 at DYD438 (SQ 7, 14, 16, and 17). Table S1: haplogroups of AMEL-Y-null Pakistani males determined through web-based software Nevgen Y-DNA haplogroup predictor. Table S2: maximum number of mutations at each character studies in haplotypes of AMEL-Y-null Pakistani males. Two characters are appended to the locus name (e.g., "DYS389II") to distinguish between repeat numbers (e.g., "aa" $=27$ repeats, “ab" $=28$ repeats). (Supplementary Materials)

\section{References}

[1] K. M. Sullivan, A. Mannucci, C. P. Kimpton, and P. Gill, "A rapid and quantitative DNA sex test: fluorescence-based PCR analysis of X-Y homologous gene amelogenin," BioTechniques, vol. 15, no. 4, pp. 636-640, 1993.

[2] M. Faerman, G. Kahila, P. Smith et al., "DNA analysis reveals the sex of infanticide victims," Nature, vol. 385, no. 6613, pp. 212-213, 1997.

[3] A. C. Stone, G. R. Milner, S. Pääbo, and M. Stoneking, "Sex determination of ancient human skeletons using DNA," American Journal of Physical Anthropology, vol. 99, no. 2, pp. 231-238, 1996.

[4] J. M. Butler, Forensic DNA Typing: Biology, Technology, and Genetics of STR Markers, Elsevier, Amsterdam, Netherlands, 2005.

[5] E. Butler and R. Li, "Genetic markers for sex identification in forensic DNA analysis," Journal Forensic Investigation, vol. 2, no. 3, pp. 1-10, 2014.

[6] Y. Nakahori, K. Hamano, M. Iwaya, and Y. Nakagome, "Sex identification by polymerase chain reaction using X-Y homologous primer," American Journal of Medical Genetics, vol. 39, no. 4, pp. 472-473, 1991.

[7] S. Sasaki and H. Shimokawa, "The amelogenin gene," International Journal of Developmental Biology, vol. 39, no. 1, pp. 127-133, 2003.

[8] A. Akane, H. Shiono, K. Matsubara et al., "Sex identification of forensic specimens by polymerase chain reaction (PCR): two alternative methods," Forensic Science International, vol. 49, no. 1, pp. 81-88, 1991.

[9] A. Mannucci, K. M. Sullivan, P. L. Ivanov, and P. Gill, "Forensic application of a rapid and quantitative DNA sex test by amplification of the X-Y homologous gene amelogenin," International Journal of Legal Medicine, vol. 106, no. 4, pp. 190-193, 1994.

[10] A. Akane, S. Seki, H. Shiono et al., "Sex determination of forensic samples by dual PCR amplification of an X-Y homologous gene," Forensic Science International, vol. 52, no. 2, pp. 143-148, 1992.

[11] H. Haas-Rochholz and G. Weiler, "Additional primer sets for an amelogenin gene PCR-based DNA-sex test," International Journal of Legal Medicine, vol. 110, no. 6, pp. 312-315, 1997.

[12] A. E. Codina, H. Niederstätter, and W. Parson, "“GenderPlex” a PCR multiplex for reliable gender determination of degraded human DNA samples and complex gender constellations," International Journal of Legal Medicine, vol. 123, no. 6, pp. 459-464, 2009.

[13] M. Steinlechner, B. Berger, H. Niederstätter, and W. Parson, "Rare failures in the amelogenin sex test," International Journal of Legal Medicine, vol. 116, no. 2, pp. 117-120, 2002.

[14] V. K. Kashyap, S. Sahoo, T. Sitalaximi, and R. Trivedi, "Deletions in the Y-derived amelogenin gene fragment in the Indian population," BMC Medical Genetics, vol. 7, no. 1, p. 37, 2006.

[15] R. Kumagai, Y. Sasaki, T. Tokuta, H. Biwasaka, and Y. Aoki, "DNA analysis of family members with deletion in Yp11.2 region containing amelogenin locus," Legal Medicine, vol. 10, no. 1, pp. 39-42, 2008.

[16] S. Turrina, G. Filippini, G. Voglino, and D. De Leo, “Two additional reports of deletion on the short arm of the $\mathrm{Y}$ chromosome," Forensic Science International: Genetics, vol. 5, no. 3, pp. 242-246, 2011. 
[17] D. Marjanović, N. Pojskić, B. Kalamujić et al., "Most recent investigation of peopling of Bosnia and Herzegovina: DNA approach," Documenta Praehistorica, vol. 33, pp. 21-28, 2006.

[18] T. W. Athey, "Haplogroup prediction from Y-STR values using a Bayesian-allele-frequency approach," Journal of $\mathrm{Ge}$ netic Genealogy, vol. 2, no. 2, pp. 34-39, 2006.

[19] J. Cullen and K. Nordtvedt, World Haplogroup \& Haplo-I Subclade Predictor, 2008, http://members.bex.net/jtcullen515/ haplotest.htm.

[20] M. C. Gentula and A. Nevski, "Y-DNA haplogroup predictor-NevGen," 2015, Reference 20 weblink https://www. nevgen.org/.

[21] K. L. Young, G. Sun, R. Deka, and M. H. Crawford, "Paternal genetic history of the Basque population of Spain," Human Biology, vol. 83, no. 4, pp. 455-475, 2011.

[22] C. Núñez, M. Geppert, M. Baeta, L. Roewer, and B. MartínezJarreta, "Y chromosome haplogroup diversity in a Mestizo population of Nicaragua," Forensic Science International: Genetics, vol. 6, no. 6, pp. e192-e195, 2012.

[23] E. Petrejčíková, Č. Jana, D. Hronská et al., "Y-SNP analysis versus Y-haplogroup predictor in the Slovak population," Anthropologischer Anzeiger, vol. 71, no. 3, pp. 275-285, 2014.

[24] C. Gurkan, H. Sevay, D. K. Demirdov et al., "Turkish Cypriot paternal lineages bear an autochthonous character and closest resemblance to those from neighbouring Near Eastern populations," Annals of Human Biology, vol. 44, no. 2, pp. 164-174, 2017.

[25] Y Chromosome Consortium, "A nomenclature system for the tree of human Y-chromosomal binary haplogroups," Genome Research, vol. 12, no. 2, pp. 339-348, 2002.

[26] S. Willuweit and L. Roewer, "The new Y chromosome haplotype reference database," Forensic Science International: Genetics, vol. 15, pp. 43-48, 2015.

[27] L. Roewer, "The Y-Chromosome Haplotype Reference Database (YHRD)-publicly available reference and research datasets for the forensic interpretation of Y-chromosome STR profiles," in Handbook of Forensic Genetics: Biodiversity and Heredity in Civil and Criminal Investigation, pp. 231-248, World Scientific, Singapore, 2017.

[28] S. Köchl, H. Niederstätter, and W. Parson, "DNA extraction and quantitation of forensic samples using the phenolchloroform method and real-time PCR," in Forensic DNA Typing Protocols, pp. 13-29, Springer, Berlin, Germany, 2005.

[29] M. Barbisin, R. Fang, C. E. O’Shea, L. M. Calandro, M. R. Furtado, and J. G. Shewale, "Developmental validation of the quantifiler ${ }^{\circledR}$ duo DNA quantification kit for simultaneous quantification of total human and human male DNA and detection of PCR inhibitors in biological samples," Journal of Forensic Sciences, vol. 54, no. 2, pp. 305-319, 2009.

[30] M. L. Pontes, D. Abrantes, G. Lima et al., "AmpFesTR ${ }^{\circledR}$ Y-filer ${ }^{\mathrm{TM}}$ : a new tool for rapid Y-STR forensic haplotyping," International Congress Series, vol. 1288, pp. 180-182, 2006.

[31] D. Y. Wang, C.-W. Chang, R. E. Lagacé, L. M. Calandro, and L. K. Hennessy, "Developmental validation of the AmpFeSTR ${ }^{\circledR}$ Identifiler ${ }^{\circledR}$ Plus PCR Amplification Kit: an established multiplex assay with improved performance," Journal of Forensic Sciences, vol. 57, no. 2, pp. 453-465, 2012.

[32] M. J. Ludeman, Z. Chang, J. J. Mulero et al., "Developmental validation of GlobalFiler ${ }^{\mathrm{TM}}$ PCR amplification kit: a 6-dye multiplex assay designed for amplification of casework samples," International Journal of Legal Medicine, vol. 132, no. 6, pp. 1555-1573, 2018.
[33] R. Schmidt, Evaluation of GeneMapper ${ }^{\circledR} I D-X$ and GeneMarker ${ }^{\circledR}$ HID for Use at the NYC OCME, Marshall University, Huntington, West Virginia, 2011.

[34] H.-J. Bandelt, P. Forster, and A. Röhl, "Median-joining networks for inferring intraspecific phylogenies," Molecular Biology and Evolution, vol. 16, no. 1, pp. 37-48, 1999.

[35] P. Forster, A. Röhl, P. Lünnemann et al., "A short tandem repeat-based phylogeny for the human Y chromosome," The American Journal of Human Genetics, vol. 67, no. 1, pp. 182-196, 2000.

[36] R. Qamar, A. Qasim, M. Aisha et al., "Y-chromosomal DNA variation in Pakistan," The American Journal of Human Genetics, vol. 70, no. 5, pp. 1107-1124, 2002.

[37] D. R. Hares, "Expanding the CODIS core loci in the United States," Forensic Science International: Genetics, vol. 6, no. 1, pp. e52-e54, 2012.

[38] F. R. Santos, A. Pandya, and C. Tyler-Smith, "Reliability of DNAbased sex tests," Nature Genetics, vol. 18, no. 2, p. 103, 1998.

[39] K. Thangaraj, A. G. Reddy, and L. Singh, "Is the amelogenin gene reliable for gender identification in forensic casework and prenatal diagnosis?" International Journal of Legal Medicine, vol. 116, no. 2, pp. 121-123, 2002.

[40] W. Lattanzi, M. C. D. Giacomo, G. M. Lenato et al., "A large interstitial deletion encompassing the amelogenin gene on the short arm of the Y chromosome," Human Genetics, vol. 116, no. 5, pp. 395-401, 2005.

[41] Y. M. Chang, R. Perumal, P. Y. Keat, R. Y. Y. Yong, D. L. C. Kuehn, and L. Burgoyne, "A distinct Y-STR haplotype for Amelogenin negative males characterized by a large Yp11.2 (DYS458-MSY1-AMEL-Y) deletion," Forensic Science International, vol. 166, no. 2-3, pp. 115-120, 2007.

[42] Y. Ma, J.-Z. Kuang, J. Zhang et al., "Y chromosome interstitial deletion induced Y-STR allele dropout in AMELY-negative individuals," International Journal of Legal Medicine, vol. 126, no. 5, pp. 713-724, 2012.

[43] E. Ehler, R. Marvan, and D. Vanek, "Evaluation of 14 Ychromosomal short tandem repeat haplotype with focus on DYS449, DYS456, and DYS458: Czech population sample," Croatian Medical Journal, vol. 51, no. 1, pp. 54-60, 2010.

[44] J. B. Cheng, Q. Liu, F. Long, D. X. Huang, and S. H. Yi, "Analysis of the Yp11.2 deletion region of phenotypically normal males with an AMELY-null allele in the Chinese han population," Genetic Testing and Molecular Biomarkers, vol. 23, no. 5, pp. 359-362, 2019.

[45] A. M. Cadenas, M. Regueiro, T. Gayden et al., "Male amelogenin dropouts: phylogenetic context, origins and implications," Forensic Science International, vol. 166, no. 2-3, pp. 155-163, 2007.

[46] F. D. Giacomo, F. Luca, L. O. Popa et al., "Y chromosomal haplogroup J as a signature of the post-neolithic colonization of Europe," Human Genetics, vol. 115, no. 5, pp. 357-371, 2004.

[47] O. Semino, C. Magri, G. Benuzzi et al., "Origin, diffusion, and differentiation of Y-chromosome haplogroups $\mathrm{E}$ and $\mathrm{J}$ : inferences on the neolithization of Europe and later migratory events in the Mediterranean area," The American Journal of Human Genetics, vol. 74, no. 5, pp. 1023-1034, 2004.

[48] D. G. Mahal and I. G. Matsoukas, "Y-STR haplogroup diversity in the Jat population reveals several different ancient origins," Frontiers in Genetics, vol. 8, p. 121, 2017.

[49] P. Forster, R. Harding, A. Torroni, and H.-J. Bandelt, "Origin and evolution of Native American mtDNA variation: a reappraisal," American Journal of Human Genetics, vol. 59, no. 4, p. $935,1996$. 